\title{
SISTEMA DE REPRODUÇÃO EM POPULAÇÕES DE Eschweilera ovata (Cambess.) Miers ${ }^{1}$
}

\author{
Eduardo Gusson², Alexandre Magno Sebbenn³ e Paulo Yoshio Kageyama²
}

\begin{abstract}
RESUMO - O sistema de reprodução de duas populações de Eschweilera ovata foi quantificado por análise de isoenzimas em estrutura de progênies, usando-se os modelos misto de reprodução e de cruzamentos correlacionados. Desvios do modelo misto de reprodução foram evidenciados entre as freqüências alélicas dos óvulos e do pólen e pela heterogeneidade nas freqüências alélicas do pólen que fecundou as diferentes árvores. A taxa de cruzamento multilocos foi alta nas populações Camarugipe $\left(\hat{t}_{m}=0,999 \pm 0,004\right)$ e Itaparica $\left(\hat{t}_{m}=0,985 \pm 0,023\right)$. A alta variação na taxa de cruzamento individual $(\hat{t}$ variando de 0,320 a 1,000) indicou que a espécie não é auto-incompatível. Diferenças positivas e significativamente diferentes de zero foram detectadas entre as taxas de cruzamento multiloco e uniloco, evidenciando cruzamentos endogâmicos nas populações Camarugipe $\left(\hat{t}_{m}-\hat{t}_{s}=0,066 \pm 0,014\right)$ e Itaparica $\left(\hat{t}_{m}-\hat{t}_{s}=0,073 \pm 0,016\right)$ e possível estruturação genética espacial. Valores altos de cruzamentos biparentais foram detectados nessas populações (Camarugipe, $\hat{r}_{p}=0,577 \pm 0,088$; e Itaparica, $\hat{r}_{p}=0,423 \pm 0,070$ ), demonstrando que as progênies são constituídas principalmente por misturas de meios-irmãos e irmãos-completos. O coeficiente de coancestria nas progênies de ambas as populações (Camarugipe, $\hat{\theta}_{x y}=0,211$; e Itaparica, $\hat{\theta}_{x y}=0,191$ ) foi superior ao esperado em progênies de meios-irmãos $(0,125)$. Os resultados foram discutidos sob a óptica de amostragens para melhoramento, conservação genética e coleta de sementes para recuperação ambiental.
\end{abstract}

Palavras-chave: Eschweilera ovata, espécies arbóreas tropicais, taxa de cruzamento, cruzamentos endogâmicos, coancestria e tamanho efetivo de variância.

\section{MATING SYSTEM IN Eschweilera ovata (Cambess.) Miers POPULATIONS}

\begin{abstract}
The mating system of two populations of Eschweilera ovata was studied by allozymes analysis of progeny arrays using the mixed-mating model and correlated mating model. Deviations from mixed-mating model were evident from differences in pollen and ovule allele frequencies and allele frequency heterogeneity of pollen pools that fertilized the different trees. The multilocus outcrossing rate was high in both Camarugipe $\left(\hat{t}_{m}=0.999 \pm 0.004\right)$ and Itaparica populations $\left(\hat{t}_{m}=0.985 \pm 0.023\right)$. The high variation in individual outcrossing rate $(\hat{t}$ ranged from 0.320 to 1.000$)$ indicated that the species is not self-incompatible. Positive differences and significantly different from zero between multilocus and single locus outcrossing rate were detected, indicating biparental inbreeding in both Camarugipe $\left(\hat{t}_{m}-\hat{t}_{s}=0.066 \pm 0.014\right)$ and Itaparica populations $\left(\hat{t}_{m}-\hat{t}_{s}=0.073 \pm 0.016\right)$ and possible spatial genetic structuring. Higher values of correlated mating were detected in the populations (Camarugipe, $\hat{r}_{p}=0.577 \pm 0.088$; Itaparica $\hat{r}_{p}=0.423 \pm 0.070$ ), showing that the families consisted mainly of half-sib and full-sib mixtures. The coancestry coefficient within families from both populations (Camarugipe, $\hat{\theta}_{x y}=0.211$; Itaparica $\left.\hat{\theta}_{x y}=0.191\right)$ was higher than the expected in half-sib families (0.125). The results were
\end{abstract}

\footnotetext{
${ }^{1}$ Recebido em $1^{\circ} .06 .2004$ e aceito para publicação em 05.04.2006.

${ }^{2}$ Departamento de Ciências Florestais da ESALQ/USP, Av. Pádua Dias, 15, 13418-900 Piracicaba, SP.

${ }^{3}$ Instituto Florestal de São Paulo, Caixa Postal 1322, 01059-970 São Paulo, SP.
} 
discussed from the point of view of sampling for improvement, genetic conservation and seed collection aiming at environmental recovery.

Keywords: Eschweilera ovata, tropical tree species, outcrossing rate, biparental inbreeding, coancestry and effective variance size.

\section{INTRODUÇÃO}

O estudo do sistema de reprodução permite estimar a taxa de cruzamento entre indivíduos e determinar o modo de transmissão dos genes de uma geração para outra (BROWN,1990). Seu conhecimento é fundamental em qualquer espécie que se pretenda manipular. $\mathrm{O}$ sistema de reprodução, juntamente com os mecanismos de dispersão de pólen e sementes, tem papel central na determinação da estrutura genética espacial e temporal das populações (HAMRICK, 1983; HAMRICK e LOVELLESS, 1986). Estudos visando ao melhoramento, conservação genética e produção de sementes devem ser baseados no conhecimento do modo de reprodução da espécie sob consideração.

Em espécies arbóreas, a reprodução pode ocorrer por cruzamentos aleatórios, cruzamentos biparentais, autofecundações, apomixia e suas combinações. Esses modos de reprodução podem ser eficientemente elucidados, usando marcadores genéticos. Estudos com espécies arbóreas tropicais baseados em dados de marcadores isoenzimáticos vêm demonstrado que a grande maioria dessas é alógama ou de sistema misto, com predomínio de cruzamentos (O'MALLEY e BAWA 1987; MURAWSKI et al., 1990; MURAWSKI, 1995; SOUZA et al., 2003).

A Floresta Atlântica, representante de uma das mais complexas diversidades de espécies e altos índices de endemismo, encontra-se entre os biomas mais ameaçados, restando atualmente cerca de apenas 7,3\% de sua cobertura original. Particularmente na região costeira do Nordeste, as modificações das paisagens naturais continuam apresentando riscos eminentes para várias espécies de plantas, das quais muitas são endêmicas (MORI e PRANCE, 1981). O agravante é que essa região abriga centros secundários de distribuição para algumas famílias, destacando-se Lecythidaceae, com algumas espécies de grande importância econômica (MORI, 1995). Dentre essas, Eschweilera ovata (Cambess.) Miers - Lecythidaceae, ou biriba, é uma espécie arbórea tropical comum, climácica, que se comporta como pioneira antrópica em áreas degradadas exclusiva das matas pluviais Atlântica e Amazônica (MORI, 1995; LORENZI, 1998). A espécie possui diversos usos, por exemplo a confecção do arco (verga) do berimbau, instrumento musical utilizado como componente principal da orquestra da capoeira e mais típico símbolo áudiovisual do estado da Bahia. A espécie também é considerada chave em processos de recuperação de áreas degradadas (MONTAGNINI et al., 1995). Suas flores são hermafroditas, polinizadas freqüentemente por abelhas do gênero Xylocopa (MORI e PRANCE, 1981; MORI, 1988; KNUDSEN e MORI, 1996). Apesar da ausência de informações disponíveis para a espécie, estudos com outras plantas da família indicam que os frutos de Lecythidaceae costumam ser dispersos por morcegos, aves, pequenos roedores e símios (PRANCE e MORI, 1978; STEVENSON, 2001). Estudos do sistema de reprodução na Lecythidaceae Cariniana legalis Mart. O. Ktze. detectaram elevada taxa de cruzamento (SEBBENN et al., 2000). Contudo, não existem estudos do sistema de reprodução em $E$. ovata, mas acredita-se que a taxa de cruzamento também seja alta, em virtude de sua alta densidade populacional em ocorrência natural.

O objetivo deste trabalho foi investigar os padrões de reprodução em populações naturais de $E$. ovata, usando-se eletroforese de isoenzimas e os modelos de reprodução mista e cruzamentos correlacionados, com o intuito de disponibilizar informações voltadas para a conservação genética da espécie em áreas de florestas sob domínio da Mata Atlântica.

\section{MATERIAL E MÉTODOS}

\section{1. Áreas de estudo e amostragem}

O estudo do sistema de reprodução de $E$. ovata abrangeu duas populações naturais de E. ovata, na região da Grande Salvador, Estado da Bahia: Mata de Itaparica e Mata de Camarugipe. A Mata de Itapatica localiza-se no Município de Itaparica, BA, nas proximidades da localidade denominada Tairu. Aárea está contida em um contínuo florestal bastante extenso, formado por um mosaico de estruturas fisionômicas 
distintas determinadas em razão das diferentes interferências antrópicas sofridas ou, ainda, atuantes, apresentando desde capoeirões em processo de regeneração até áreas com fisionomias da Floresta Ombrófila Densa secundária. A segunda área, a Mata de Camarugipe, localiza-se no Município de Malhada, $\mathrm{BA}$, próxima à Reserva particular de Sapiranga. Essa meta é considerada pelos pesquisadores locais como uma das florestas que menos sofreu a ação do homem na região norte de Salvador, tendo cerca de 1.300 ha de floresta contínua. A distância da Mata de Camarugipe com relação à Itaparica é de 95,1 km. As coordenadas geográficas aproximadas das áreas são: $12^{\circ} 30^{\prime} 43^{\prime \prime} \mathrm{S}$ e $38^{\circ} 01^{\prime} 87^{\prime \prime} \mathrm{W}$ na população Camarugipe e $13^{\circ} 01^{\prime}$ 90" S e 38 43' 97" W na Itaparica. As duas áreas se caracterizam por apresentar vegetação característica da Floresta Ombrófila Densa de tabuleiros de planícies litorâneas, as quais possuem uma estratificação evidente com cerca de 15 a $20 \mathrm{~m}$ de altura, salvo algumas espécies emergentes, com cerca de 10 a $15 \mathrm{~m}$.

Amostras de 20 progênies de polinização aberta foram coletadas em cada população. De cada árvore foram colhidas sementes em várias partes da copa, sendo analisadas por eletroforese de isoenzimas 10 plântulas por progênies. As sementes foram germinadas em recipientes gerbox com vermiculita, separadamente por árvore-matriz. A germinação foi realizada em incubadora, sob condições controladas de luz e temperatura. Essas condições consistiram em fotoperíodo de oito horas com temperatura de $30{ }^{\circ} \mathrm{C}$, simulando o período de luz, e de $25^{\circ} \mathrm{C}$, durante o período de escuro (16 horas). Os gerboxes que apresentavam mais que 10 plântulas germinadas eram retirados da incubadora e colocados em ambiente natural, para continuidade do processo de desenvolvimento das mudas. O maior número de sementes germinadas foi observado entre 20 e 25 dias após incubação.

Adicionalmente, para amostragem das árvores adultas fez-se um transecto, cuja distância variou em função do sucesso da identificação do número de árvores previamente estabelecido, o qual foi de 60 indivíduos. Consideraram-se adultas as árvores que com DAP de aproximadamente $10 \mathrm{~cm}(\mathrm{CAP} \geq 30 \mathrm{~cm})$. Essas populações apresentaram demografia muito semelhante, sendo de 52 e 56 árvores/ha nas populações Camarugipe e Itaparica, respectivamente. As amostras de tecidos foliares de árvores adultas foram embaladas em sacos de papel identificados com o número da árvore de origem e acondicionados em ambiente refrigerado por no máximo cinco dias e transportadas ao laboratório, onde foi realizado o processo de extração das isoenzimas.

\subsection{Protocolo de isoenzimas}

A eletroforese de isoenzimas foi a horizontal, conduzida em meio suporte de gel horizontal de amido de milho (penetrose) e amido de batata ( $13 \%$ de amido). A extração das isoenzimas foi efetuada usando-se o tampão de extração de número 1, citado em Alfenas (1998). Após a extração, wicks (papel whatman n. 3) foram embebidos nos extratos obtidos, colocados em microtubos e armazenados em um "freezer" $\left(-80^{\circ} \mathrm{C}\right)$, onde ficaram até o momento da realização da corrida eletroforética. Os sistemas-tampão gel/eletrodo usado foram citrato-morfolina, $\mathrm{pH} 7,1 / 6,1$, e o Tris-citrato, pH 7,5/7,5. A constituição e descrição dos tampões e das soluções de revelação das diferentes enzimas encontram-se em Alfenas (1998). As enzimas PGI, MDH, DIA e NADHDH foram reveladas no tampão gel/eletrodo citrato-morfolina e ACP, G6PDH, IDH e 6PGDH no Triscitrato. Esses oito sistemas isoenzimáticos revelaram 13 locos. Destes, apenas cinco foram possíveis de serem revelados nos adultos; nas progênies, todos foram revelados. Contudo, estudo prévio da herança e do desequilíbrio gamético nesses locos indicou a presença de ligação entre três pares de locos, envolvendo cinco locos (GUSSON e SEBBENN, 2004). Por isso, foram excluídos das análises os locos Pgi-2 e Dia-2, de forma a quebrar qualquer associação aparente entre alelos de diferentes locos.

\subsection{Análise estatística}

O sistema de reprodução das populações de $E$. ovata foi analisado com base nos modelos de reprodução mista (RITLAND e JAIN, 1981) e cruzamentos correlacionados (RITLAND, 1989), com o auxílio do programa "Multilocos MLTR" (RITLAND, 1997). Os parâmetros estimados foram: $i$ ) a taxa populacional de cruzamento multiloco $\left(t_{m}\right)$, pelo método de máxima verossimilhança (Algoritmo EM, ExpectationMaximization); ii) a taxa populacional de cruzamento uniloco $\left(t_{s}\right)$; iii) a taxa de cruzamento entre aparentados $\left.\left(t_{m}-t_{s}\right) ; i v\right)$ a taxa individual de cruzamentos multilocos $(t) ; v)$ as freqüências alélicas dos óvulos e do pólen $(o$ e $p)$; vi) o índice de fixação nas árvores maternas $\left(F_{m}\right)$; vii) a correlação de autofecundação $\left(r_{s}\right)$; e viii) a correlação de paternidade $\left(r_{p}\right)$. As pressuposições

R. Árvore, Viçosa-MG, v.30, n.4, p.491-502, 2006 
do modelo misto são dadas em Ritland e Jain (1981). O erro-padrão das estimativas dos parâmetros foi obtido por 500 reamostragens bootstraps. O teste de cruzamentos aleatórios foi avaliado pelo teste de homogeneidade entre as freqüências alélicas dos óvulos vs. pólen, calculando-se o estimador $\hat{F}_{S T}$ (NEI, 1977). O teste estatístico para verificar se a estimativa de $F_{S T}$, em cada loco, é diferente de zero foi o qui-quadrado, $\chi^{2}=2 n \hat{F}_{S T}$ $(k-1)$, com $(k-1)(s-1)$ graus de liberdade, proposto por Workman e Niswander (1970), em que: $n=$ número de indivíduos nos dois grupos, $k=$ número de alelos e $s=$ número de grupos. Os índices de fixação para adultos $(F)$ e progênies $\left(F_{p}\right)$ foram estimados juntamente com os respectivos intervalos de confiança por 10.000 reamostragens bootstraps, usando-se o programa GDA (LEWIS e ZAYKIN, 2002).

O coeficiente de coancestria $\left(\theta_{x y}\right)$ dentro de progênies foi estimado do coeficiente de correlação de parentesco $\left(\hat{r}_{x y}\right)$, entre plantas dentro de progênies, descrito em Ritland (1989):

$$
\hat{r}_{x y}=0,25\left(1+\hat{F}_{p}\right)\left[4 \hat{s}+\left(\hat{t}^{2}+\hat{s} \hat{t} \hat{r}_{s}\right)\left(1+\hat{r}_{p}\right)\right]
$$

sendo $\hat{F}_{p}$ o estimador do índice de fixação (coeficiente de endogamia) da geração parental e $\hat{s}$ a estimativa da taxa de autofecundação, dada por $1-\hat{t}_{m}$. Os demais estimadores foram definidos anteriormente. Como em espécies diplóides, na ausência de endogamia o coeficiente de parentesco $\left(r_{x y}\right)$ é o dobro do coeficiente de coancestria $\left(\theta_{x y}\right)$, têm-se que $\hat{\theta}_{x y}=\hat{r}_{x y} / 2$, e podese obter o coeficiente de coancestria do coeficiente de parentesco. O tamanho efetivo de variância de uma simples progênie foi estimado com base na variância amostral de um alelo, segundo derivações de Cockerham (1969), e usando uma população idealizada como referência, como descrito em Sebbenn (2003).

\section{RESULTADOS E DISCUSSÃO}

\subsection{Freqüiências alélicas dos óvulos e pólen}

A estimativa da divergência genética entre as freqüências alélicas dos óvulos e do pólen revelou diferenças significativas nos locos Mdh-2, Pgi-l e Dia-1 na população Camarugipe e nos locos $M d h$ 2, Acp-3 e Dia-1 na população Itaparica (Quadro 1). Diferenças entre as freqüências alélicas do pólen e dos óvulos podem ser atribuídas a diferenças nas funções masculina e feminina das plantas, imigração de pólen de fora das populações amostradas, seleção entre o período de polinização e análise de isoenzimas, devido à amostragem não representativa das árvores maternas (RITLAND e JAIN, 1981) e a desvios de cruzamentos aleatórios causados por autofecundações, cruzamentos biparentais, cruzamentos endogâmicos (cruzamentos entre indivíduos parentes) e variação na fenologia de florescimento. Dentre esses fatores, os mais prováveis nas presentes populações de E. ovata são a amostragem não-representativa das árvores maternas e os desvios de cruzamentos aleatórios.

\subsection{Homogeneidade nas freqüências alélicas de árvores adultas, óvulos e pólen}

Todos os locos, nas duas populações, apresentaram divergência genética $\left(\hat{F}_{S T}\right)$ significativa entre as freqüências alélicas do pólen que fecundou cada uma das árvores maternas, com exceção do loco $M d h-1$ na população Camarugipe. Isso demonstra que o pólen que fecundou as árvores maternas não era homogêneo e que os cruzamentos não foram aleatórios. A homogeneidade nas freqüências alélicas é um dos pressupostos básicos do modelo de reprodução mista de Ritland e Jain (1981). Contudo, desvios dessa pressuposição abrem espaço para o entendimento de outros fatores do processo de reprodução. Por exemplo, a heterogeneidade nas frequiências alélicas pode ser causada por cruzamentos biparentais, que por sua vez podem estar associados a pequenas vizinhanças. Outra causa pode ser a variação espacial e temporal entre árvores na fenologia de florescimento e fecundidade (MITTON, 1992) e a proporção de árvores adultas que se reproduzem dentro da estação (MURAWSKI e HAMRICK, 1991).

A comparação entre as freqüências alélicas das árvores adultas e os óvulos e das árvores adultas e o pólen revelou divergência genética $\left(\hat{F}_{S T}\right)$ significativa em quase todos os locos examinados, à exceção do loco Pgi-1 na população Itaparicae e do $6 p g d h-1$ na população Camarugipe. Esses resultados indicam que as 20 árvores maternas amostradas em cada população não representavam as árvores adultas das populações, em termos de freqüências alélicas, e para representálas seria necessário um número maior de árvores maternas. Provavelmente, 50 a 60 árvores seriam suficientes, considerando-se os resultados obtidos por El-Kassaby e Sziklai (1983), que estudaram o efeito da amostragem 
para representar freqüências alélicas em populações de espécies arbóreas. Contudo, tendo em vista o alto custo e a dificuldade de genotipar progênies de 50 a 60 árvores de uma simples população, acredita-se que a coleta de sementes em 30 a 35 árvores já melhoraria substancialmente a amostragem.

A heterogeneidade nas freqüências alélicas das árvores adultas e do pólen também indica que este último não era uma amostra representativa da população. A causa pode ser atribuída a cruzamentos biparentais, autofecundações, cruzamentos entre parentes e a fluxo de pólen de fora da população. É difícil determinar qual foi a real causa, mas provavelmente todos esses fatores tenham contribuído, de alguma forma, para esse resultado.
Embora tenham sido detectados desvios das pressuposições do modelo de reprodução mista, segundo Ritland e Jain (1981), tais desvios têm pouco efeito nas estimativas multilocos de cruzamento, sendo a pressuposição de ausência de ligação ou o equilíbrio gamético entre locos a mais importante.

\subsection{Taxa de cruzamentos multiloco e uniloco}

A estimativa da taxa de cruzamento multiloco (Quadro 3) foi de 0,999 na população Camarugipe e 0,985 na população Itaparica. Essas estimativas não foram significativamente diferentes da unidade, podendo ser consideradas altas em ambas as populações, além de indicar que a espécie se reproduz predominantemente por cruzamentos.

Quadro 1 - Estimativa da divergência genética $\left(\hat{F}_{S T}\right)$ entre as freqüências alélicas do pólen e dos óvulos, tamanho amostral $(n)$ e teste de qui-quadrado $\left(\chi^{2}\right)$ em $E$. ovata

Table 1 - Estimates of genetic divergence $\left(\hat{F}_{S T}\right)$ between allelic frequencies of pollen and ovule pools, sample size $(n)$ and qui-square test $\left(\chi^{2}\right)$ in E. ovata

\begin{tabular}{|c|c|c|c|c|c|c|c|c|c|c|c|c|c|}
\hline \multirow[b]{2}{*}{ Loco } & \multirow[b]{2}{*}{ Alelo } & \multicolumn{6}{|c|}{ População Camarugipe } & \multicolumn{6}{|c|}{ População Itaparica } \\
\hline & & Pólen & Óvulo & $\hat{F}_{S T}$ & $n$ & GL & $\chi^{2}$ & Pólen & Óvulo & $\hat{F}_{S T}$ & $n$ & GL & $\chi^{2}$ \\
\hline \multirow[t]{2}{*}{$M d h-1$} & 1 & 0,005 & 0,025 & & & & & 0,005 & 0,024 & & & & \\
\hline & 2 & 0,995 & 0,975 & 0,007 & 193 & 1 & 1,31 & 0,995 & 0,976 & 0,006 & 199 & 1 & 1,26 \\
\hline \multirow[t]{3}{*}{$M d h-2$} & 1 & 0,021 & 0,024 & & & & & 0,051 & 0,005 & & & & \\
\hline & 2 & 0,890 & 0,732 & & & & & 0,660 & 0,925 & & & & \\
\hline & 3 & 0,089 & 0,244 & 0,039 & 194 & 2 & $15,13 * *$ & 0,289 & 0,025 & 0,101 & 188 & 2 & $38,15 * *$ \\
\hline \multirow[t]{3}{*}{$6 p g d h$} & 1 & 0,440 & 0,550 & & & & & 0,384 & 0,405 & & & & \\
\hline & 2 & 0,380 & 0,250 & & & & & 0,396 & 0,336 & & & & \\
\hline & 3 & 0,180 & 0,200 & 0,012 & 192 & 2 & $4, .55$ & 0,220 & 0,260 & 0,009 & 197 & 2 & 3,41 \\
\hline \multirow[t]{2}{*}{ Acp } & 1 & 0,208 & 0,300 & & & & & 0,274 & 0,387 & & & & \\
\hline & 2 & 0,792 & 0,700 & 0,011 & 196 & 1 & 2,19 & 0,726 & 0,613 & 0,054 & 196 & 1 & $10,55 * *$ \\
\hline \multirow[t]{2}{*}{ G6pdh } & 1 & 0,444 & 0,400 & & & & & 0,447 & 0,386 & & & & \\
\hline & 2 & 0,556 & 0,600 & 0,002 & 182 & 1 & 0,36 & 0,553 & 0,614 & 0,016 & 196 & 1 & 3,08 \\
\hline \multirow[t]{2}{*}{$P g i-1$} & $\begin{array}{l}1 \\
2\end{array}$ & $\begin{array}{l}0,151 \\
0,604\end{array}$ & $\begin{array}{l}0,100 \\
0,450\end{array}$ & & & & & $\begin{array}{l}0,132 \\
0,688\end{array}$ & $\begin{array}{l}0,104 \\
0,682\end{array}$ & & & & \\
\hline & 3 & 0,245 & 0,450 & 0,029 & 192 & 2 & $11,20 * *$ & 0,180 & 0,215 & 0,004 & 188 & 2 & 1,63 \\
\hline \multirow[t]{3}{*}{ Dia-1 } & 1 & 0,249 & 0,463 & & & & & 0,582 & 0,429 & & & & \\
\hline & 2 & 0,746 & 0,512 & & & & & 0,418 & 0,572 & & & & \\
\hline & 3 & 0,006 & 0,024 & 0,053 & 179 & 2 & $18,93 * *$ & - & 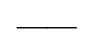 & 0,096 & 174 & 1 & $16,74 * *$ \\
\hline \multirow[t]{3}{*}{ Dia-3 } & 1 & 0,106 & 0,075 & & & & & 0,029 & 0,052 & & & & \\
\hline & 2 & 0,753 & 0,725 & & & & & 0,864 & 0,845 & & & & \\
\hline & 3 & 0,141 & 0,200 & 0,003 & 169 & 2 & 1.06 & 0,108 & 0,104 & 0,003 & 143 & 2 & 0,96 \\
\hline \multirow[t]{2}{*}{ Nadhdh-1 } & -11 & 0,667 & 0,725 & & & & & 0,877 & 0,876 & & & & \\
\hline & 2 & 0,333 & 0,275 & 0,004 & 100 & 2 & 1,06 & 0,123 & 0,124 & 0,000 & 120 & 1 & 0,00 \\
\hline \multirow{3}{*}{ Nadhdh- } & -21 & 0,623 & 0,683 & & & & & 0,629 & 0,656 & & & & \\
\hline & 2 & 0,344 & 0,293 & & & & & 0,365 & 0,329 & & & & \\
\hline & 3 & 0,034 & 0,024 & 0,003 & 149 & 1 & 0,99 & 0,006 & 0,015 & 0,005 & 166 & 2 & 1,52 \\
\hline
\end{tabular}

** $P<0,01 \mathrm{e} * P<0,05$. 
Quadro 2 - Estimativa da divergência genética $\left(\hat{F}_{S T}\right)$ entre as freqüências alélicas do pólen de diferentes árvores, árvores adultas e os óvulos e entre as árvores adultas e o pólen em duas populações de E. ovata

Table 2 - Estimates of genetic divergence $\left(\hat{F}_{S T}\right)$ between allelic frequencies of pollen pools from different trees, adult trees and vules, and adult trees and pollen pool in two E. ovata populations

\begin{tabular}{|c|c|c|c|c|c|c|}
\hline \multirow[b]{2}{*}{ Loco } & \multicolumn{2}{|c|}{ Heterogeneidade do Pólen } & \multicolumn{2}{|c|}{ Adultos vs Óvulos } & \multicolumn{2}{|c|}{ Adultos vs Pólen } \\
\hline & Canarugipe & Itaparica & Canarugipe & Itaparica & Canarugipe & Itaparica \\
\hline$\overline{M d h-1}$ & 0,052 & $0,138 * *$ & - & - & & $-\quad-$ \\
\hline$M d h-2$ & $0,043 * *$ & $0,645 * *$ & - & - & & - \\
\hline $6 p g d h$ & $0,164 * *$ & $0,255 * *$ & $0,024 * *$ & $0,011 * *$ & 0,004 & $0,011 * *$ \\
\hline$A c p$ & $0,110 * *$ & $0,122 * *$ & $0,092 * *$ & $0,136 * *$ & $0,380 * *$ & $0,015 * *$ \\
\hline G6pdh & $0,134 * *$ & $0,244 * *$ & - & - & - & - \\
\hline$P g i-1$ & $0,070 * *$ & $0,153 * *$ & $0,033 * *$ & 0,002 & $0,018 * *$ & $0,009 *$ \\
\hline Dia-1 & $0,084 * *$ & $0,170 * *$ & $0,011 * *$ & $0,045 * *$ & $0,123 * *$ & $0,011 * *$ \\
\hline Dia-3 & $0,096 * *$ & $0,127 * *$ & - & - & - & - \\
\hline Nadh-1 & $0,114 *$ & $0,157 * *$ & - & - & - & - \\
\hline Nadh-2 & $0,115 *$ & $0,125 * *$ & - & - & - & - \\
\hline
\end{tabular}

$* * P<0,01 \mathrm{e} * P<0,05$.

A taxa de cruzamento uniloco foi menor do que a de cruzamento multiloco, com valores de 0,933 na população Camarugipe e de 0,912 na Itaparica. Essas estimativas evidenciam $m$ ausência de mecanismos de autoincompatibilidade na espécie. Comparando as estimativas da taxa de cruzamento multiloco com a calculada para a média das espécies arbóreas tropicais $(0,880 \pm 0,040$; SEBBENN, 2001), observa-se que os valores obtidos nas populações de E. ovata são bem superiores a esse e diferem estatisticamente em ambas as populações estudadas. Altas estimativas de cruzamentos são prerrogativas de alta taxa de recombinação e variabilidade genética. A reprodução por cruzamentos favorece a recombinação e a formação de ampla variedade de genótipos, que podem conferir alto potencial evolutivo para as espécies e fazer frente à seleção natural nos mais diversos ambientes de sua ocorrência.

A taxa de cruzamento individual variou consideravelmente entre árvores maternas (Quadro 4). Na população Camarugipe, a taxa de cruzamento oscilou de 0,390 a 1,000 e na explorada, de 0,320 a 1,0000. Entretanto, apenas $10 \%$ das estimativas em ambas as populações foram menores do que 0,5 , e $20 \%$ foram estatisticamente diferentes da unidade, reforçando o fato de que a espécie se reproduz por sistema misto, com predomínio de cruzamentos e que, provavelmente, não existem mecanismos de auto-incompatibilidade na espécie.

Quadro 3 - Estimativa de parâmetros do sistema de reprodução em populações de E. ovata Table 3 - Estimates of mating system parameters in E. ovata populations

\begin{tabular}{|c|c|c|}
\hline \multirow[b]{2}{*}{ Parâmetros } & \multicolumn{2}{|c|}{ Populações } \\
\hline & Camarugipe & Itaparica \\
\hline Taxa de cruzamento multiloco $\left(t_{m}\right)$ & $0,999(0,004)$ & $0,985(0,023)$ \\
\hline Taxa de cruzamento uniloco $\left(t_{s}\right)$ & $0,933(0,011)$ & $0,912(0,017)$ \\
\hline Taxa de cruzamento entre parentes $\left(t_{m}-t_{s}\right)$ & $0,066(0,012)$ & $0,073(0,016)$ \\
\hline Correlação de autofecundação $\left(r_{s}\right)$ & $0,107(0,001)$ & $0,100(0,008)$ \\
\hline Correlação de paternidade $\left(r_{p}\right)$ & $0,577(0,088)$ & $0,423(0,070)$ \\
\hline $\mathrm{N}^{\circ}$ médio de árvores doadoras de pólen $\left(1 / r_{p}\right)$ & 1,7 & 2,4 \\
\hline Proporção de irmãos de autofecundação $\left(P_{I A}\right)^{p}$ & $0,2 \%$ & $2,2 \%$ \\
\hline Proporção de irmãos-completos $\left(P_{I C}\right)$ & $57,6 \%$ & $41,7 \%$ \\
\hline Proporção de meios-irmãos $\left(P_{M I}\right)$ & $42,2 \%$ & $56,8 \%$ \\
\hline Índice de fixação na árvores adultas $(F)$ & $0,032[-0,224$ a 0,254$]$ & $0,193[-0,020$ a 0,441$]$ \\
\hline Índice de fixação nas progênies $\left(F_{P}\right)$ & $0,071[-0,0520$ a 0,1750$]$ & $0,061[-0,0784$ a 0,1864$]$ \\
\hline Coancestria dentro de progênies $\left(q_{F}\right)$ & 0,211 & 0,191 \\
\hline Tamanho efetivo de variância $\left(N_{e(v)}\right)$ & 2,05 & 2,22 \\
\hline Número de matrizes para reter o $N_{e}=50(\mathrm{~m})$ & 25 & 23 \\
\hline
\end{tabular}

[ ] Intervalo de confiança a 95\% de probabilidade, obtido por 10.000 reamostragens bootstrap sobre locos.

( ) Erro-padrão de cada estimador, obtido por 500 reamostragens bootstrap. 
Quadro 4 - Estimativa da taxa de cruzamento multiloco individual por planta materna $(\hat{t})$ em população de $E$. ovata Table 4 - Estimates of individual outcrossing rate $(\hat{t})$ in E. ovata populations

\begin{tabular}{cccccc}
\hline & \multicolumn{2}{c}{ População Camarugipe } & & \multicolumn{3}{c}{ População Itaparica } \\
\cline { 1 - 2 } \cline { 5 - 6 } Progênies & $n$ & $\hat{t}$ & Progênies & N & $\hat{t}$ \\
\hline 1 & 10 & $1,00(0,00)$ & 1 & 10 & $0,91(0,09)$ \\
2 & 10 & $1,00(0,00)$ & 2 & 10 & $0,33(0,17)$ \\
3 & 10 & $0,41(0,18)$ & 3 & 10 & $1,00(0,00)$ \\
4 & 10 & $1,00(0,00)$ & 4 & 10 & $1,00(0,00)$ \\
5 & 10 & $1,00(0,04)$ & 5 & 10 & $0,93(0,08)$ \\
6 & 10 & $0,39(0,23)$ & 6 & 10 & $1,00(0,00)$ \\
7 & 10 & $0,98(0,07)$ & 7 & 10 & $1,00(0,00)$ \\
8 & 10 & $1,00(0,00)$ & 8 & 10 & $1,00(0,00)$ \\
9 & 10 & $0,53(0,18)$ & 9 & 10 & $1,00(0,00)$ \\
10 & 10 & $1,00(0,00)$ & 10 & 10 & $0,32(0,21)$ \\
11 & 10 & $0,97(0,06)$ & 11 & 10 & $1,00(0,05)$ \\
12 & 10 & $0,99(0,10)$ & 12 & 10 & $0,91(0,09)$ \\
13 & 10 & $0,82(0,13)$ & 13 & 10 & $0,96(0,10)$ \\
14 & 10 & $0,92(0,09)$ & 14 & 10 & $0,71(0,15)$ \\
15 & 10 & $1,00(0,00)$ & 15 & 10 & $0,91(0,10)$ \\
16 & 10 & $0,98(0,11)$ & 16 & 10 & $0,72(0,23)$ \\
17 & 10 & $1,00(0,00)$ & 17 & 10 & $1,00(0,00)$ \\
18 & 10 & $1,00(0,03)$ & 18 & 10 & $1,00(0,00)$ \\
19 & 10 & $1,00(0,00)$ & 19 & 10 & $1,00(0,00)$ \\
20 & 10 & $1,00(0,00)$ & 20 & 10 & $0,83(0,13)$ \\
\hline
\end{tabular}

( ): Erro-padrão de $\hat{t}$, obtido por 500 reamostragens bootstrap sobre locos.

\subsection{Taxa de cruzamento entre parentes}

A estimativa de diferença entre a taxa de cruzamentos multiloco e uniloco $\left(\hat{t}_{m}-\hat{t}_{s}\right)$ tem sido utilizada para quantificar a ocorrência de cruzamentos endogâmicos ou, em outros termos, entre indivíduos aparentados. Os resultados aqui obtidos revelaram cruzamentos entre parentes em ambas as populações: 0,066 na população Camarugipe e 0,073 na Itaparica (Quadro 3). Esses valores não diferem estatisticamente entre si e podem ser considerados moderadamente baixos, porém em ambas as populações eles são significativamente diferentes de zero. O cruzamento entre parentes, além da autofecundação, é outra forma de geração de endogamia nas populações de espécies arbóreas, embora seus efeitos sejam mais brandos do que os da autofecundação em si. Tendo em vista que a endogamia observada nas progênies $\left(\hat{F}_{p}\right)$ da população Camarugipe foi de 0,071 , que a endogamia pode ser gerada por autofecundações $(\hat{s}=1-\hat{t})$ e por cruzamentos entre parentes e somandose a taxa de autofecundação mais a taxa de cruzamento entre parentes, conclui-se que praticamente $100 \%$ dessa endogamia foi gerada por cruzamento entre parentes nessa população (Quadro 3). Aplicando o mesmo raciocínio de cálculo com os dados da população Itaparica, determina-se que $76,8 \%$ da endogamia foi gerada por cruzamentos entre parentes, sendo o restante atribuído à autofecundação $(23,2 \%)$. Ainda, visto que em espécies de cruzamentos a endogamia nas progênies é igual à coancestria entre os parentais cruzados (LINDGREN et al., 1996), pode-se afirmar que o parentesco entre as árvores responsáveis pela taxa de cruzamento entre indivíduos parentes é próximo ao de primos de primeiro grau $(0,0625)$ ou, resumidamente, existe parentesco nas populações, o qual é, em média, próximo ao esperado entre primos de primeiro grau.

\subsection{Taxa de cruzamentos correlacionados}

As estimativas das correlações de autofecundação $\left(\hat{r}_{s}\right)$, ou a probabilidade de encontrar um indivíduo gerado por autofecundação onde foi encontrado outro de autofecundação, foram relativamente baixas em ambas as populações e não diferentes estatisticamente entre si, tendo apresentado valores de 0,107 $\pm 0,001 \mathrm{na}$ população Camarugipe e 0,100 $\pm 0,008$ na Itaparica. Esse resultado indica que não existe forte tendência

R. Árvore, Viçosa-MG, v.30, n.4, p.491-502, 2006 
de algumas plantas maternas deixarem mais descendentes por autofecundação ou cruzamentos do que outra, estando os indivíduos advindos de autofecundação, distribuídos aleatoriamente dentro das progênies. Isso reforça a conclusão de que a espécie é autocompatível.

A correlação $r_{p}$ mede a proporção de indivíduos de cruzamentos que foram gerados por cruzamentos biparentais (cruzamentos sucessivos entre mesmo par de parentais maternos e paternos) (RITLAND, 1989). A estimativa da correlação $r_{p}$ em E. ovata (Quadro 3) foi elevada e significativamente diferente de zero, nas duas populações, com valores de 0,577 $\pm 0,088$ e 0,423 $\pm 0,070$, respectivamente, na população Camarugipe e Itaparica. Também se verificou que elas não diferem estatisticamente entre si. Esses resultados apontam que parte das progênies de cruzamentos foi gerada pelo mesmo parental materno e paterno e que as progênies não são compostas exclusivamente por meiosirmãos, mas por uma mistura de meios-irmãos, irmãoscompletos e irmãos de autofecundação. Sun e Ritland (1998) atribuíram os cruzamentos biparentais ao comportamento dos polinizadores, visitando de forma sistemática árvores próximas e pequeno número de vizinhos próximos, e ao assincronismo no florescimento das árvores. Além disso, variações ambientais podem também afetar o comportamento e, ou, a densidade das populações de animais polinizadores, levando à alterações na taxa de cruzamento das espécies em diferentes populações (MURAWSKI, 1995).

Souza et al. (2003) afirmaram que o sistema misto de reprodução normalmente é conceituado como a mistura de cruzamentos aleatórios e autofecundações, excluída a ocorrência de cruzamentos biparentais, que é outra forma de reprodução, a qual também pode causar desvios de cruzamentos aleatórios, mesmo em espécies obrigatoriamente de cruzamento (espécies dióicas). Em C. legalis (SEBBENN et al., 2000), espécie da mesma família da $E$. ovata (Lecythidaceae), as correlações de paternidade variaram entre populações de 0,212 a 0,324. Em populações de Esenbeckia leiocarpa Engl. (Seoane et al., 2001), as estimativas das correlações de paternidade variaram de 0,749 a 0,986, sendo estas umas das mais altas detectadas em espécies arbóreas tropicais. Em Tabebuia cassinoides (Lam.) A.P. de Candolle (SEBBENN et al., 2001), foi detectado maior correlação de paternidade em uma população natural $(0,547)$, em comparação com uma população manejada $(0,295)$. Isso também foi observado aqui, e, embora as correlações não diferisse estatisticamente entre si, notou-se maior correlação $r_{p}$ na população não explorada (Camarugipe). No entanto, Murawski e Hamrick (1991) observaram que, em populações de espécies arbóreas de baixa densidade populacional, o pólen dos cruzamentos era menos diversificado do que em espécies de alta densidade. Em estudo recente realizado com Pachira quinta (Jacq.) Alverson (FUCHS et al., 2003), uma espécie arbórea tropical das florestas da Costa Rica, comparando a estimativa da correlação de paternidade em uma população adensada em relação a outra com árvores distantes entre si por pelo menos $500 \mathrm{~m}$, detectaram-se $r_{p}$ de 0,470 na população adensada e de 0,740 na amostra de árvores isoladas. Os referidos autores atribuíram a maior correlação de paternidade na última população ao isolamento das árvores e à baixa densidade populacional.

A partir da correlação de paternidade é possível estimar o número médio de indivíduos polinizadores efetivos por árvore $\left(1 / \hat{r}_{p}\right)$, ou seja, a média do número provável de indivíduos que contribuíram com pólen no evento de reprodução de uma árvore materna. $\mathrm{O}$ número de árvores efetivamente polinizadoras foi extremamente baixo, com média de dois indivíduos por árvore. Estudos semelhantes sobre o sistema de reprodução em espécies arbóreas tropicais corroboraram com esse resultado. Alves et al. (2003), estudando uma população de Teobroma grandiflorum (Willd. \& Spreng.) Schum. encontraram que o número médio de polinizadores era de um a dois indivíduos. Em Eucalyptus rameliana F. Muell (SAMPSON, 1998), Picea mariana (Mill.) BSP (PERRY e BOUSQUET, 2001) e Grevillea iaspicula McGill (HOEBEE e YOUNG, 2001), o número de polinizadores não foi superior a 7. Esses resultados vêm de encontro à teoria geral de que a polinização natural em espécies arbóreas é realizada a partir de grande número de plantas doadoras de pólen.

Combinando a estimativa da correlação de paternidade $\left(\hat{r}_{p}\right)$ com a estimativa de taxa de cruzamento multiloco $\left(\hat{t}_{m}\right)$, é possível conhecer a proporção dos diferentes tipos de parentesco dentro das progênies. A proporção de irmãos de autofecundação foi nula na população Camarugipe e de apenas $2,2 \%$ na população Itaparica. A proporção de irmãos-completos foi de 56,6\% e $41,7 \%$ nas populações Camarugipe e Itaparica, respectivamente, e a proporção de meios-irmãos foi de $42,2 \%$ e 56,8\% nas populações Camarugipe e Itaparica, 
respectivamente. Isso demonstra que as progênies de E. ovata da população Camarugipe são compostas em maior proporção por irmãos-completos, enquanto na população Itaparica a proporção de meios-irmãos é maior.

\section{6. Índices de fixação}

O índice de fixação mede o excesso ou deficiência de homozigotos em relação as proporções esperadas em populações em equilíbrio de Hardy-Weinberg. Na população Camarugipe, a estimativa do índice de fixação mostrou maior endogamia nas progênies $\left(\hat{F}_{p}=0,071\right)$, em comparação com as árvores adultas $(\hat{F}=0,032)$. O mesmo não ocorreu na população de Itaparica, em que o valor de $\hat{F}(0,193)$ foi consideravelmente maior que $\hat{F}_{p}(0,061)$. Contudo, o índice de fixação nas árvores adultas e nas progênies de ambas as populações não foi estatisticamente diferente de zero e entre si. O índice de fixação detectado na população Camarugipe indica que está ocorrendo seleção contra homozigotos, visto que a endogamia nas progênies foi superior à observada nos adultos. Resultado semelhante tem sido detectado em diversos estudos comparando gerações de árvores tropicais adultas com suas progênies (SEBBENN et al., 2001; SEOANE et al., 2001; SOUZA et al., 2003; ALVES et al., 2003).

Em espécies arbóreas de fecundação cruzada, a endogamia pode ter efeitos negativos sobre a capacidade adaptativa e reprodutiva de populações pequenas, sendo esses efeitos incrementados pela sobreposição de gerações. Em populações pequenas, na ausência de seleção contra homozigotos a taxa de endogamia e parentesco pode crescer rapidamente, levando à depressão endogâmica. Suas principais características são as perdas de vigor, fertilidade, capacidade de adaptação e reprodução (ALLARD, 1971).

\subsection{Coeficiente de coancestria e tamanho efetivo de variância}

Em concordância com as estimativas da correlação de paternidade, o valor estimado para o coeficiente de coancestria dentro de progênies de ambas as populações indica a presença de mistura de parentescos. O coeficiente de coancestria nas populações Camarugipe $\left(\hat{\theta}_{x y}=0,211\right)$ e Itaparica $\left(\hat{\theta}_{x y}=0,191\right)$ foram $40,8 \%$ e $34,5 \%$ superiores, relativamente ao esperado em progênies de meios-irmãos $(0,125)$. A maior coancestria na população Camarugipe pode ser atribuída à maior correlação de paternidade, ou seja, à maior proporção de cruzamentos biparentais, sendo a maioria das progênies geradas, aparentadas no grau de irmãoscompletos. Adicionalmente, cabe ressaltar que na população Itaparica foi detectado taxa de cruzamento entre indivíduos aparentados de 7,3\% e na Camarugipe, de $6,6 \%$, indicando que uma parte pequena, porém expressiva, das progênies geradas por cruzamentos aleatórios e biparentais deve ser aparentada em grau superior ao de meios-irmãos e irmãos-completos.

O coeficiente de coancestria $\left(\theta_{x y}\right)$ tem papel central, em programas de melhoramento e conservação genética, na estimativa do coeficiente de correlação parentesco $\left(r_{x y}\right)$ entre plantas dentro de progênies e tamanho efetivo de variância $\left(N_{e(v)}\right)$. O coeficiente de correlação é a base do cálculo da variância genética aditiva e, conseqüentemente, do coeficiente de herdabilidade e do ganho esperado na seleção. Em espécies de cruzamentos, o coeficiente de correlação de parentesco é o dobro do coeficiente de coancestria $\left(r_{x y}=2 \theta_{x y}\right)$, de forma que alterações na coancestria geram simultaneamente alterações no coeficiente de parentesco. Em progênies perfeitamente de meios-irmãos, o coeficiente de parentesco estima $25 \%$ da variação genética aditiva. No presente trabalho, a correlação de parentesco estimada do coeficiente de coancestria corresponde a 0,422 e 0,382 nas populações Camarugipe e Itaparica, respectivamente. Portanto, em termos de melhoramento, os coeficientes de correlação estimados indicam que assumir progênies de meios-irmãos para a estimativa de parâmetros genéticos em E. ovata irá gerar fortes superestimativas na variância genética aditiva e parâmetros dependentes dessa variância.

O coeficiente de coancestria também influencia o tamanho efetivo de variância $\left(N_{e(v)}\right)$, o qual mede a representatividade genética de uma população em função de alterações nas frequiências alélicas entre gerações, em razão de efeitos da deriva genética (CABALLERO, 1994). Os valores estimados de $N_{e(v)}$ foram de 2,05 na população Camarugipe e 2,22 na população Itaparica. Esses valores são basicamente a metade do valor teórico máximo esperado (aproximadamente 4) em uma simples progênie derivada de uma população idealizada (tamanho infinito, praticando cruzamentos aleatórios, sem seleção, mutação e migração e sobreposição de gerações).

R. Árvore, Viçosa-MG, v.30, n.4, p.491-502, 2006 


\subsection{Número de árvores-matriz para a coleta de sementes de polinização aberta em $E$. ovata}

O tamanho efetivo de variância permite a estimativa do número de árvores-matriz necessárias para a coleta de sementes para os mais diversos fins, como tamanhos amostrais para conservação ex situ, melhoramento genético e recuperação de áreas degradadas. Tais estimativas podem ser facilmente obtidas, dividindose um tamanho efetivo alvo (ou de referência) pelo tamanho efetivo médio de uma simples progênie da população (SEBBENN, 2002, 2003). Dentro desse contexto, o tamanho efetivo de 50 tem sido sugerido como suficiente para manter o coeficiente de endogamia a uma taxa de $1 \%$ por geração, até 10 gerações, em locos com dois alelos, em populações de espécies com gerações discretas (FRANKEL e SOULÉ, 1981). Objetivando reter o $N_{e}$ de 50, em amostras de E. ovata, determinou-se que o número de árvores-matriz necessárias para a coleta de sementes é de 25 e 23 nas populações Camarugipe e Itaparica, respectivamente. Assim, havendo interesse na conservação ex situ no curto prazo ou coleta de sementes para a recuperação de áreas degradas com a espécie, aproximadamente 23 indivíduos seriam o número médio mínimo de árvoresmatriz de uma população a serem consideradas na coleta de sementes. Esse número é aproximadamente o dobro do sugerido na literatura (13 árvores) e comumente utilizado como referência na coleta de sementes para formação de mudas a serem utilizadas em plantios de restauração florestal.

\section{AGRADECIMENTOS}

Este estudo foi possível graças à concessão da bolsa CAPES de mestrado a E.G. e CNPq de Produtividade em Pesquisa a A.M.S. e P.Y.K; à FAPESP, pelo financiamento da pesquisa; aos técnicos e pósgraduandos do LARGE/ESALQ/USP e ao biólogo Leonardo Marquez Pacheco, pela contribuição ao desenvolvimento deste trabalho; e aos três revisores anônimos, pelas valiosas correções e construtivos comentários no prévio manuscrito deste artigo.

\section{REFERÊNCIAS BIBLIOGRÁFICAS}

\section{ALFENAS, S.A. Eletroforese de}

isoenzimas e proteínas afins: fundamentos e aplicações em plantas e microrganismos. Viçosa: Universidade Federal de Viçosa, 1998. 574 p.

\author{
ALlard, R.W. Princípios do \\ melhoramento genético das plantas. \\ São Paulo: Edgard BLUCHER. 1971. 381 p.
}

ALVES, R.M. et al. Mating system in natural population of Theobroma grandiflorum (Willd ex Spreng) Shumm. Genetics and Molecular Biology, v. 79, n. 2, p. 20-31, 2003.

CABALlERO, A. Developments in the prediction of effective population size. Heredity, v. 73, p. 657-679, 1994.

COCKERHAM, C.C. Variance of gene frequencies. Evolution, v. 23, p. 72-84, 1969.

EL-KASSABY, Y.A.; SZIKLAI, O. Effect of sample size on the precision of the estimate of allozyme frequencies in a natural stand of Douglas-Fir. Egyptian Journal of Genetics and Citology, v. 24, p. 345-360, 1983.

FRANKEL, O.H.; SOULÉ, M.S. Conservation and Evolution. Cambridge: Cambridge University Press, 1981. 327 p.

FUCHS, E.J.; LOBO, J.A.; QUESADA, M. Effects of forest fragmentation and flowering phonology on the reproductive success and mating patterns of the tropical dry forest tree Pachira quinata. Conservation Biology, v. 17, n. 1, p. 149-157, 2003.

GUSSON, E.; SEBBENN, A.M. Herança e equilíbrio gamético em locos isoenzimáticos de Eschweilera ovata. Revista do Instituto Florestal, v. 67, n. 1, p., 129-136, 2004.

HAMRICK, J.L. The distribution of genetic variation within and among natural plant population. In: SCHONE-WALD-COX, C.M. et al. Genetics and conservation. Menlo Park: Benjamin Cummings. 1983. p. 335-348.

HAMRICK, J.L.; LOVELESS, M.D. The influence of seed dispersal mechanisms on the genetic structure of plant populations. In: ESTRADA, A.; FLEMING, T.H. (Ed.). Forgivers and seed dispersal. Athens: Junk Publishers, 1986. p. 124-145. 
HOEBEE, S.E.; YOUNG, A.G. Low neighborhood size and high interpopulation differentiation in the endangered shrub Grevillea iaspicula McGill (Proteacea). Heredity, v. 88, p. 489-496, 2001.

KNUDSEN, J.T.; MORI, S. A. Floral scents and pollination in neotropical Lecythidaceae.

Biotropica, v. 28, n. 1, p. 42-60, 1996.

LEWIS, P.O.; ZAYKIN, D. GDA - Genetic Data Analysis: version 1.1 for Windows 95/NT. http://www.lewis.eeb.uconn.edu/lewishome/. 2002.

LINDGREN, D.; GEA, L.; JEFFERSON, P. Loss of genetic diversity by status number. Silvae Genetica, v. 45, p. 52-59, 1996.

LORENZI, H. Árvores brasileiras: manual de identificação e cultivo de plantas arbóreas nativas do Brasil. Nova Odessa: Plantarum, 1998. v. 2.

MITTON, J.B. The dynamic mating systems of conifers. In: Population genetics of forest trees. In: ADAMS, W.T. et al. (Ed.). INTERNATIONAL SYMPOSIUM ON POPULATION GENETICS OF FOREST TREES, 1992, Dordrecht. Proceeding. Dordrecht: Kluwer Verlag, 1992.p. 197-216.

MONTAGNINI F.; FANZERES, A.; DA VINHA, S.G. The potentials of 20 indigenous tree species for soil rehabilitation in the Atlantic forest region of Bahia, Brazil. Journal of Applied Ecology, v. 32, p. 841-856, 1995.

MORI, S.A. Biologia da polinização em Lecythidaceae. Acta Botânica Brasileira, v.1, n. 2, p. 121-124, 1988.

MORI, S.A. Observações sobre as espécies de Lecythidaceae do leste do Brasil. Boletim de Botânica, v. 14, p. 1-31, 1995.

MORI, S.A.; PRANCE., G.T. Relações entre a classificação genérica de Lecythidaceae do novo mundo e seus polinizadores e dispersadores. Revista Brasileira de Botânica, v. 4, p. 31-37, 1981.

MORI, S.A.; PRANCE, G.T. Flora Neotropica: Lecythidaceae. New York: Botanical Garden. 1990. 376 p. (Monograph 21).
MURAWSKI, D.A. Reproductive biology and genetics of tropical trees from canopy perspective. In: LOWMAN, M.D.; NADKARNI, N.M. (Ed.). Forest canopies. New York: Academic Press, 1995. p. 457-493.

MURAWSKI, D.A.; HAMRICK, J.L. The effect of the density of flowering individuals on the mating systems of nine tropical tree species. Heredity, v. 67, p. 167-174, 1991.

MURAWSKI, D.A. et al. Mating system of two Bombacaceous trees of a neotropical moist forest. Oecologia, v. 82, p. 501-506, 1990.

NEI, M. F-statistics and analysis of gene diversity in subdivided populations. Annals of Human Genetics, v. 41, p. 225-233, 1977.

O’MALLEY, D.M.; BAWA, K.S. Mating system of a tropical rain forest tree species.

American Journal of Botany, v. 74, n. 8, p. 1143-1149, 1987.

PERRY, D.J.; BOUSQUET, J. Genetic diversity and mating system of post-fire and porstharvest black spruce: an investigation using codominant sequence-tagged-site (STS) markers. Canadian Journal of Forest Resources, v. 31, p. 32-40, 2001.

PRANCE, G. T.; MORI, Scott A. Observations on the fruits and seeds of neotropical Lecythidaceae. Brittonia, v. 30, p. 21-33, 1978.

RITLAND, K. Correlated matings in the partial selfer Mimulus guttatus. Evolution, v. 43, n. 4, p. 848-859, 1989.

RITLAND, K. Multilocus mating system program MLTR. Version 1.1. Toronto: University of Toronto. $<$ http// kritland@.interchange.ubc.ca>. 1997.

RITLAND, K.; JAIN, S. A model for the estimation of outcrossing rate and gene frequencies using independent loci. Heredity, v. 47, p. 35-52, 1981.

SAMPSON, J.F. Multiple paternity in Eucalyptus rameliana (Myrtaceae). Heredity, v. 81, p 349-355, 1998.

R. Árvore, Viçosa-MG, v.30, n.4, p.491-502, 2006 
SEBBENN, A. M. Estudo em populações de jequitibá [Cariniana legalis (MART.) KTZE] em teste de progênie por caracteres quantitativos e isoenzimas. 2001. 191f. Tese (Doutorado em Genética e Melhoramento) - Escola Superior de Agricultura “Luiz de Queiroz”, Piracicaba, 2001.

SEBBENN, A.M. Número de árvores matrizes e conceitos genéticos na coleta de sementes para reflorestamentos com espécies nativas. Revista do Instituto Florestal, v. 14, n. 2, p. 115-132, 2002.

SEBBENN, A.M. Tamanho amostral para conservação ex situ de espécies arbóreas com sistema misto de reprodução. Revista do Instituto Florestal, v. 15, n. 2, 147-162, 2003.

SEBBENN, A.M. et al. Taxa de cruzamento em populações de Cariniana legalis (Mart.) O. Ktze.: Implicações para a conservação e o melhoramento genético. Scientia Forestalis, n. 58, p. 25-40, 2000.

SEBBENN, A.M. et al. Estrutura genética em populações de Tabebuia cassinoides: Implicações para o manejo florestal e a conservação genética. Revista do Instituto Florestal, v. 13, n. 2, p. 93-113, 2001.
SEOANE, C.E.C.; SEBBENN, A.M.; KAGEYAMA, P.Y Sistema reprodutivo em populações de Esenbeckia leiocarpa. Revista do Instituto Florestal, v. 13, n. 1, p. 19-26, 2001.

SOUZA, L.M.F.I.; KAGEYAMA,P.Y.; SEBBENN, A.M. Sistema de reprodução em população de Chorisia speciosa A. St.-Hil (Bombacaceae).

Revista Brasileira de Botânica, v. 26, n. 1, p.113-121, 2003.

STEVENSON, P. R. The relationship between fruit production and primate abundance in neotropical communities. Biol. J. Linn. Soc., n. 72, p. 161-178, 2001.

SUN, M.; RITLAND, K. Mating system of yellow starthistle (Centaurea solstitialis), a successful colonizer in North America. Heredity, v. 80, p. 225-232, 1998.

WORKMAN, P.; NISWANDER, J.L. Population studies on southwestern Indian Tribes. II. Local genetic differentiation in the Papago. American Journal of Human Genetic, v. 22, p. 24-49, 1970. 